\title{
Successful use of two guidewires with different properties using a double-lumen catheter for postoperative biliary stricture
}

The drainage of nonphysiological postoperative biliary stricture is often challenging as the severe degree of stenosis and bending make insertion of a guidewire and catheter difficult [1-4].

A 72-year-old woman with left intrahepatic bile duct dilatation was referred to our hospital, and a left lobectomy was performed for intrahepatic cholangiocarcinoma. Preoperative examination did not show stenosis of the common bile duct (CBD). While her postoperative course was good, biliary enzyme levels gradually increased. Magnetic resonance cholangiopancreatography showed sharp bending and stenosis of the CBD with dilation of the intrahepatic bile duct ( $\mathbf{F i g} \mathbf{1}$ ).

The sharp bending of the stenosis prevented passage of a guidewire. The use of a hydrophilic guidewire (Radifocus, Terumo, Japan), which is soft and has good ability to penetrate a stenosis, facilitated insertion of the guidewire beyond the stenosis. However, the softness of the guidewire prevented the catheter from passing through the stenosis ( Fig.2). A harder guidewire was used to straighten the bend and improve the insertion performance of the device; however, the stiff guidewire could not pass readily through the stricture.

We used an uneven, double-lumen catheter (UDLC; PIOLAX, Tokyo, Japan), so called because the lumen orifices have different diameters and are located at different points on the catheter [5] ( Fig.3). The UDLC was inserted using a soft guidewire through the distal lumen, and only the tip was advanced slightly into the stricture. With the adjustment of the catheter axis, a stiff guidewire was successfully inserted beyond the stenosis through the proximal lumen. The double guidewire helped to slightly straighten the sharp bending of the stenosis ( $\mathbf{F i g}$. 4). Finally, an endoscopic nasobiliary drainage tube was placed successfully ( Fig. 5, - Video 1).

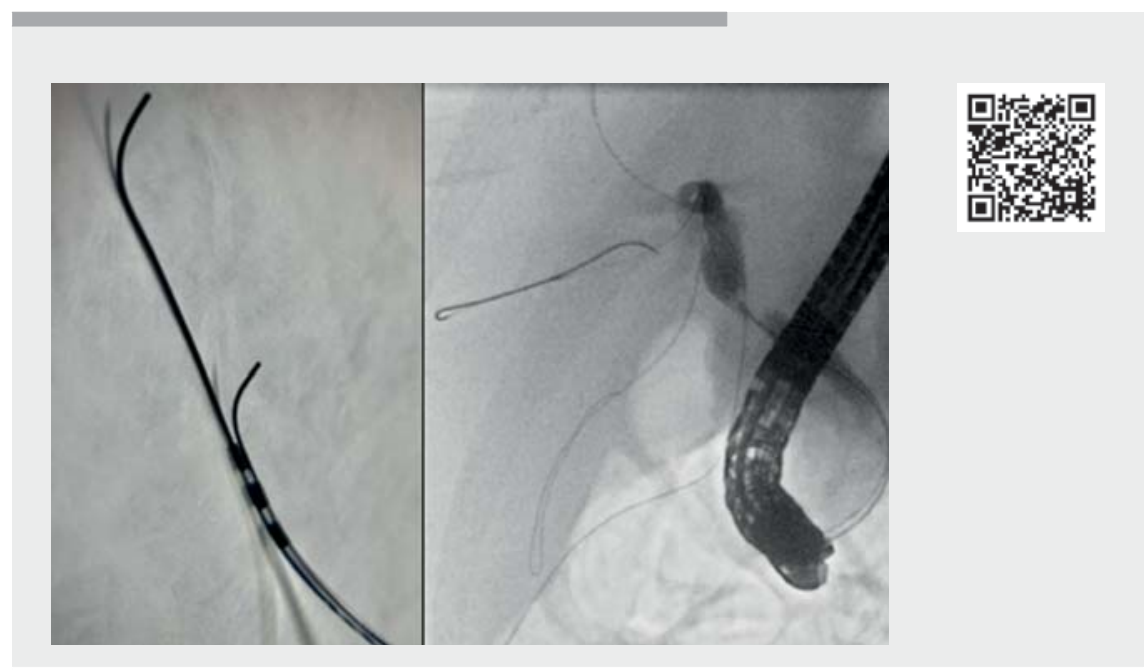

$\checkmark$ Video 1 Successful use of two guidewires with different properties using a doublelumen catheter for postoperative biliary stricture. This technique may be useful for severe biliary stenosis.
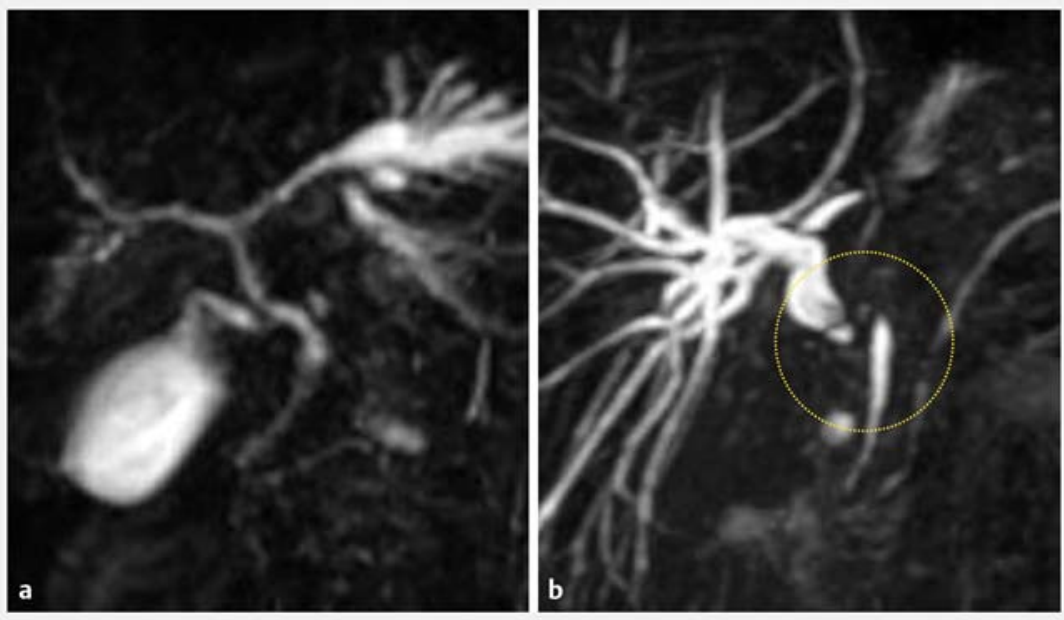

Fig. 1 Magnetic resonance cholangiopancreatography showed sharp bending and stenosis of the common bile duct with dilation of the intrahepatic bile duct after the operation. a Before surgery. b After surgery.

This double-guidewire method using a Endoscopy_UCTN_Code_TTT_1AR_2AG double-lumen catheter, which uses the properties of each guidewire according to the situation, may be useful for biliary stenosis with a severe degree of flexion. 

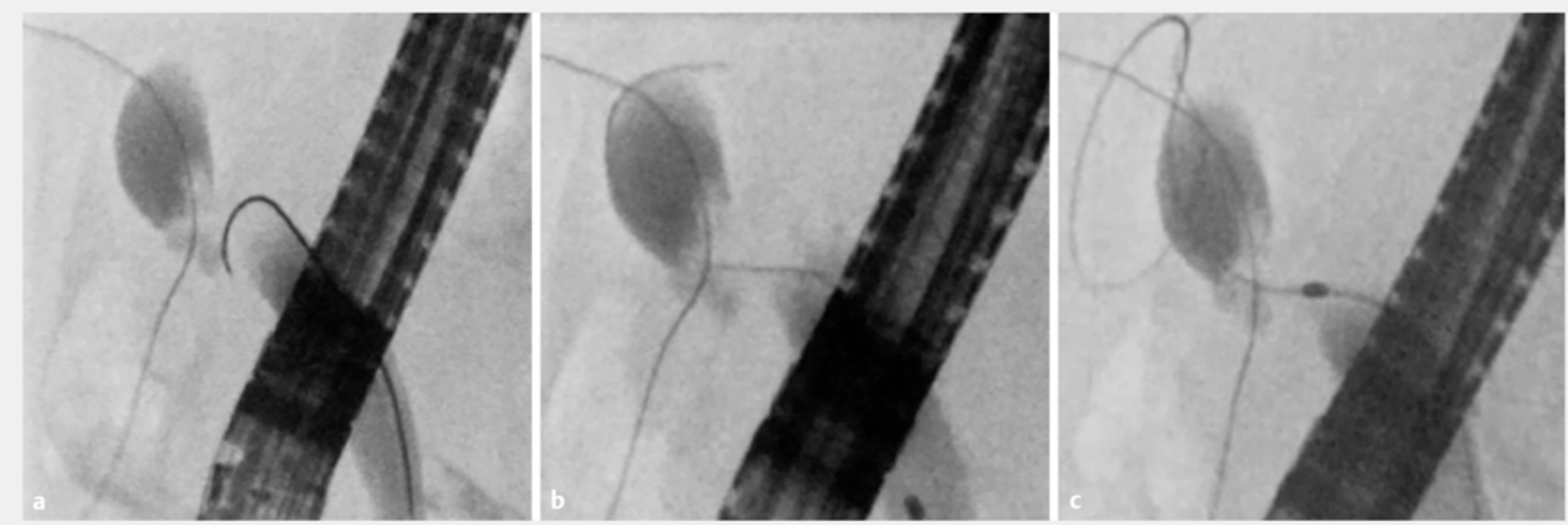

- Fig. 2 Insertion of the guidewire across the stenosis. a The sharp bending of the stenosis prevented guidewire insertion. b A hydrophilic guidewire was therefore used and could be inserted beyond the stenosis as it is softer and has a higher ability to penetrate a stenosis. c However, the softness of the guidewire prevented the catheter from passing through the stenosis.

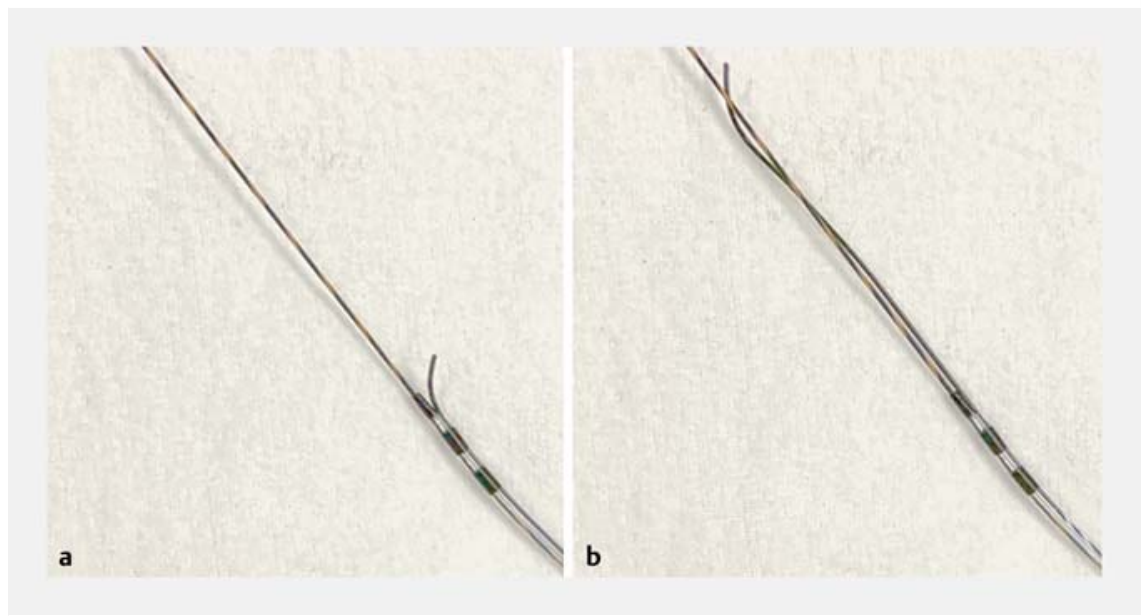

- Fig. 3 The uneven, double-lumen catheter (UDLC; PIOLAX, Tokyo, Japan). a, b The lumen orifices have different diameters and are located at different points on the catheter to enable delivery of two guidewires with different properties.

\section{Competing interests}

The authors declare that they have no conflict of interest.

The authors

Mamoru Takenaka , Tomohiro Yamazaki, Yasuo Otsuka, Rei Ishikawa, Masatoshi Kudo Department of Gastroenterology and Hepatology, Kindai University Faculty of Medicine, Osaka-Sayama, Japan

\section{Corresponding author}

\section{Mamoru Takenaka, MD}

Department of Gastroenterology and Hepatology, Kindai University Faculty of Medicine, 377-2 Ohno-Higashi, OsakaSayama, 589-8511, Japan mamoxyo45@gmail.com 

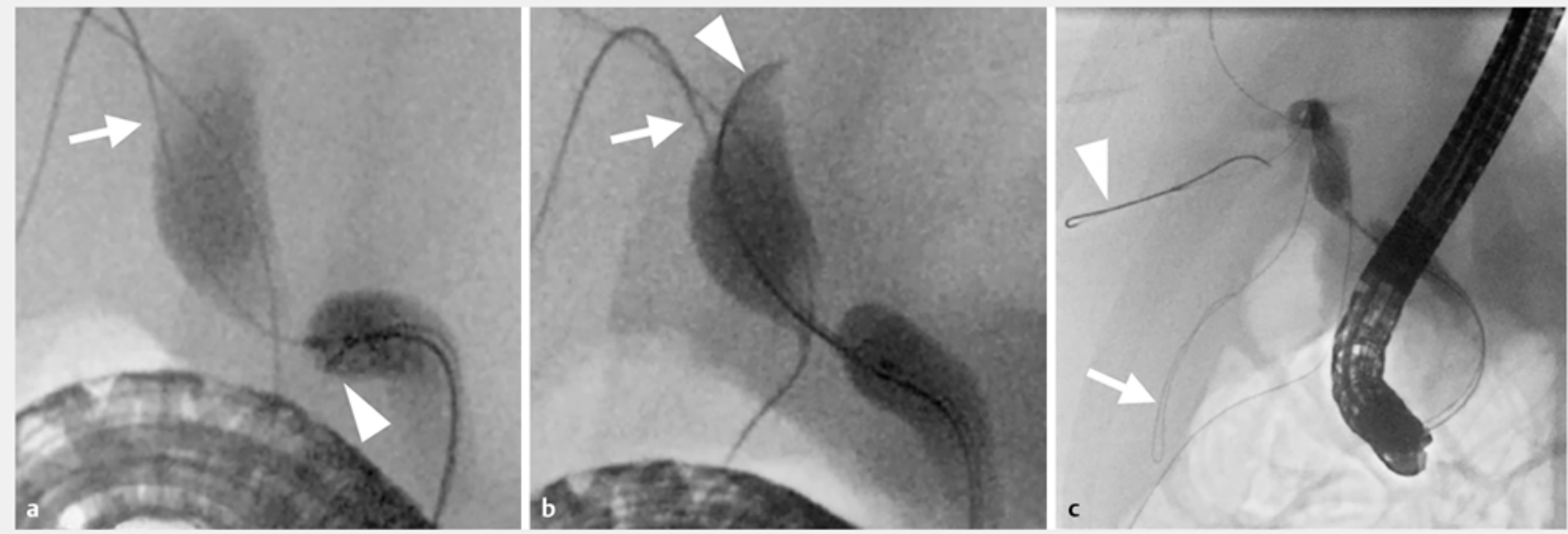

- Fig. 4 Use of the double-lumen catheter. a The uneven, double-lumen catheter was inserted using a soft guidewire (arrow) through the distal lumen and only the tip was inserted slightly into the stricture. b A stiff guidewire (arrowhead) was successfully inserted beyond the stenosis through the proximal lumen. $\mathbf{c}$ The double guidewire technique allowed the sharp bend of the stenosis to be straightened.
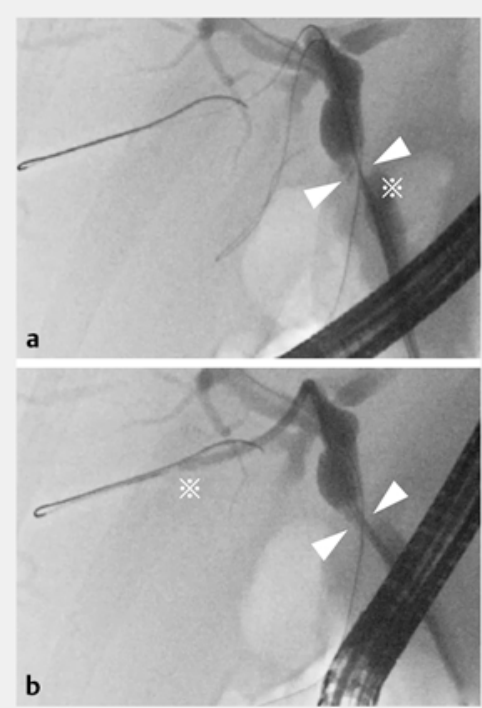

- Fig. 5 Final placement of the drainage tube. a The stenosis (arrowhead) was straightened by the double guidewire. b An endoscopic nasobiliary drainage tube $\left({ }^{*}\right)$ was placed successfully.

\section{References}

[1] Cantù P, Mauro A, Cassinotti E et al. Postoperative biliary strictures. Dig Liver Dis 2020; 52: 1421-1427

[2] Okamoto A, Minaga K, Takenaka M et al. Rendezvous within biloma technique combining percutaneous and endoscopic approaches: a novel biliary recanalization method. Endoscopy 2019; 51: E42-E44

[3] Vlaemynck K, Lahousse L, Vanlander A et al. Endoscopic management of biliary leaks: a systematic review with meta-analysis. Endoscopy 2019; 51: 1074-1081

[4] Yang Q, Liu J, Ma W et al. Efficacy of different endoscopic stents in the management of postoperative biliary strictures: a systematic review and meta-analysis. J Clin Gastroenterol 2019; 53: 418-426

[5] Takenaka M, Arisaka Y, Sakai A et al. A novel biliary cannulation method for difficult cannulation cases using a unique, uneven, double-lumen cannula (uneven method). Endoscopy 2018. doi:10.1055/a-0624-9317

\section{Bibliography}

Endoscopy 2022; 54: E190-E192

DOI $10.1055 / \mathrm{a}-1478-3248$

ISSN 0013-726X

published online 12.5 .2021

(c) 2021. Thieme. All rights reserved.

Georg Thieme Verlag KG, Rüdigerstraße 14, 70469 Stuttgart, Germany

\section{ENDOSCOPY E-VIDEOS \\ https://eref.thieme.de/e-videos}

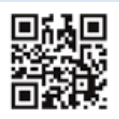

Endoscopy E-Videos is an open access online section, reporting on interesting cases and new techniques in gastroenterological endoscopy. All papers include a high quality video and all contributions are freely accessible online. Processing charges apply (currently EUR 375), discounts and wavers acc. to HINARI are available.

This section has its own submission website at

https://mc.manuscriptcentral.com/e-videos 